ORIGINAL ARTICLE

\title{
"Medicalisation of falling in love": medical students' responses to Thomas Mann's The Black Swan
}

\author{
Aino-Maija Lahtinen, Martina Torppa
}

J Med Ethics; Medical Humanities 2007;33:44-48. doi: 10.1136/jmh.2006.000245

The value of implementing literature in medical education is widely accepted. The initial responses of medical students to Thomas Mann's short story The Black Swan are described and their resources for making sense of the story are presented. Their written responses revealed that the students interpreted the story mainly through a medical framework and were capable of understanding the story's complex and existential issues related to medicine. Evident gaps in the students' interpretations and understanding are discussed and suggestions on using such kinds of intellectual texts in medical teaching are offered.

See end of article for authors' affiliations

Correspondence to M Torppa, Department of General Practice and Primary Health Care, Institute of Clinical Medicine, Faculty of Medicine, University of Helsinki, Helsinki University Central Hospital, Finland; martina.torppa@́helsinki.fi

Accepted 20 December 2006

www.medicalhumanities.com Consequently, this article attempts to show what the students understood from their reading of The
Black Swan, examines potential gaps and problems in their interpretations, and suggests ways in which subsequent exploration may offer them a more thorough understanding of the story. Thus, the educative potential of The Black Swan receives consideration from the point of view of future doctors.

\section{THOMAS MANN AND THE BLACK SWAN}

As a classic novelist, Thomas Mann depicts in his multilayered fiction, a world that is perpetually open both for his characters and, through the process of interpretation, for the reader. Many of the themes Mann dealt with in his works are drawn from personal experience, but the multilayered stories also reflect the political, philosophical and moral atmosphere of the Western world in the period of writing as well as the relationship between tradition and change. ${ }^{7}$ Besides offering a stimulating and enjoyable reading experience, his works show a lot of potential for deepening one's understanding of the human condition. The psychological portrayal of the human being and the complexity of life that Mann illuminates in his stories challenge the reader's comprehension. In repeatedly treating death and sickness, often as symbols and metaphors, Mann draws the reader's attention to the existential questions of life and thereby brings his stories close to the professional life of doctors.

Written at the age of 78 years, Thomas Mann's last completed work of fiction was first published in Germany in 1953 as Die Betrogene (German for The deceived one), and in the US I year later under the title The Black Swan. In this study, the students read Mann's novella under its original title in translation. The story is about 50-year-old Rosalie von Tümmler, an attractive and respected widow, who lives in the 1920s with her teenage son and adult daughter in Düsseldorf, Germany. Rosalie has entered the period just after menopause and experiences its typical symptoms. Unexpectedly, she falls in love with her son's 29-year old English teacher Ken Keaton. This young and liberal American arouses in Rosalie feelings of erotic desire and rejuvenation. Rosalie's passion for Ken is based largely on her physical attraction to him. Suddenly Rosalie experiences vaginal bleeding again and is convinced that her menstrual cycle has resumed, which she celebrates as a gift from nature.

Mann depicts Rosalie's vast array of feelings, such as desire, joy, shame, jealousy and suffering from her own point of view. Her daughter Anna, who observes her mother's feelings, worries about 
her mother's psychical and physical condition, the latter showing gradual signs of decline. On a Sunday, Ken joins the family on a boat trip to the Holterhof castle. During the tour, Rosalie confesses her love to Ken, and they arrange their first rendezvous, which they never keep because soon after returning home Rosalie is hospitalised for ovarian cancer. Medical cures prove useless, and at the end of the story, Rosalie succumbs to her illness.

The story is known to be based on an anecdote from real life told by Mann's wife Katia. ${ }^{8}$ Mann recorded the story during their stay in America (1938-52), and through Ken Keaton's character he may have been depicting his view of American life. When writing the medical background of his story, Mann is known to have investigated medicine and sought the advice of Doctor Frederick Rosenthal in California, USA. Mann kept close to Rosenthal's report, and described Rosalie's medical examination with accurate medical vocabulary. ${ }^{9}$ Despite the tragic elements of the story, during Mann's final period of writing, a more humorous and playfully erotic style began to emerge in his stories, particularly in The confessions of Felix Krull, confidence man (1954), and The Black Swan. ${ }^{7}$ When The Black Swan was published, a critic wrote that Mann has told us again that "nothing is simple in human life" and described the work as "a precious oasis, surely, in our desert of dusty certainties" ${ }^{10}$ In her introduction to the book in 1990, Nina Pelikan Straus states that Mann explored more concisely than ever before, themes in the story that occupied him all his life: "nature's deception of its creatures, the link between love and death, the dialogue between persons with different visions of life, and the erotic longing of the middle-aged". ${ }^{11}$ Mann's The Black Swan is written from a woman's point of view and is often considered the feminine counterpart of his Death in Venice. But unlike Death in Venice, which openly focused on homosexual love, in The Black Swan he intentionally disguised his own homosexual feelings and gave them a heterosexual guise by channelling them through his female characters. Such has been the case already in Der kleine Herr Friedmann (1897), ${ }^{12}$ through the dialogue between the novel's two main women characters, in which Mann explores his major ideas and themes. Rosalie's feelings and subjective experiences find expression through Rosalie's consciousness.

\section{THE LITERATURE SEMINAR AND PARTICIPANTS}

The literature seminar was a part of an optional study module entitled "Art and Medicine" that was carried out at the Faculty of Medicine at the University of Helsinki, Helsinki, Finland, in 2001-2. It was a pioneering study module on medical humanities and consisted of eight separate seminars (theatre, cinema, visual art, painting, literature, writing, music and drama). These seminars aimed to reflect the paradigm of modern medicine from different viewpoints and to introduce medical students to the arts and humanities. The study module was available to medical students in their clinical years (years 3-6).

Sixteen students started the study module and nine of them completed it. The completion of the study module was based on the students' active participation in the sessions and on completing the writing assignments satisfactorily. In the first meeting, the students were asked to participate in the study and all of them provided their written informed consent.

A total of 12 students participated in the literature seminar, of which 11 were women and one a man; all aged between 20-26 years. Half the participants were third-year students and half were sixth-year students. The seminar consisted of two separate sessions. In the first session, the role of literature in medical humanities was introduced and the students' reading profiles were mapped by asking them to reflect on their habits of reading literature and works they valued. At the end of the session, the students were given a copy of The Black Swan with instructions to write a free-form essay of 1-2 pages. They were allowed to explore their responses from their chosen point of view. The authors of this article acted in the dual roles of a teacher and a researcher. These dual roles posed no problem for research ethics, because the students were given an explanation of the situation at the beginning of the seminar.

\section{DATA AND ANALYSIS}

The data for this study consisted of 12 students' written essays of varying length comprising 2-4 pages. The total number of words in the data corpus was 7317; the shortest essay contained 264 words, the longest, 1019. In the initial analysis, we searched for the topics and themes that were addressed more thoroughly. Logically, the topics the students reflected on most were the same elements they found personally meaningful and understood well. In the next phase of the analysis, we focused on the topics the students considered problematic or confusing, as well as on topics associated with interpretative comments. The subsequent analysis aimed at determining the perspective through which the students understood and derived meaning from the story. The medical context of reading and previous research on The Black Swan offered the framework for this analysis. In this article, we focus solely on the students' written responses to The Black Swan. The learning outcomes of the seminar have been explored in another study. ${ }^{13}$

Although writing about reading experiences may influence readers' responses by distancing and complicating them, ${ }^{14}$ this study assumes that through written responses we can determine how the reader interprets the story, as well as identify what he or she considers personally meaningful. This study does not seek to explain an individual student's ways of constructing the meaning of the text, but rather to explore the students' responses on a group level. Their writings were thus analysed as one text corpus. ${ }^{15}$ Moreover, although the meaning of literature is fundamentally individual in nature, medical education may increase the convergence of the responses in two ways. First, through their studies, the students form an interpretative community in which interpretations tend to converge. ${ }^{16}$ Second, the students' medical education, as the context of reading, offers a similar effect. ${ }^{17}$ Reading research has also shown that with literary reading and understanding, the reader's mind functions actively on many levels. ${ }^{17}{ }^{18} \mathrm{~A}$ personal reading experience cannot be separated from its more conscious and intellectual interpretations, because in reading they blend, as do the individual and cultural interpretations. ${ }^{19}$ In the context of medical education, the professional and personal aspects also blend in the students' responses. As Rosenblatt ${ }^{17}$ states, the starting point of the written responses is no longer the text, but the meaning thought to correspond to that text. The reader-writer may return to the original text to re-examine it, but must also "find the vocabulary" for explaining his or her experience and interpretation. ${ }^{17}$

\section{FINDINGS}

\section{General notions}

Each medical student in this study approached the writing task in an individual manner. While some explored more the literal qualities of the story, others focused more on the characters' behaviour, and still others sought the author's deeper message. Despite the individual emphasis, some ways of responding emerged that could characterise the whole group. The citations of the data in which the student, whose text is cited, is identified by a number are presented as evidence of the researcher's interpretation. On the whole, the students' comments about emotional reading experiences were few. One 
student regarded the story as a "positive surprise" (s3), another as "thought provoking and cheerful" (s12). The story also provoked negative reactions, such as "I was unable to understand such a strange and rigid way of thinking and acting" (s4). The characters and the medical content of the story were the two main issues the students dealt with in their writings.

\section{The characters and their relationships}

The male characters of the story, Rosalie's son Edward and his English teacher Ken Keaton, were described as "distant" (s6, s8, s1) with only a minor role in the story. Nevertheless, Ken was also thought to have "the important function of the love object" (s10). Although secondary in the story, men still had the power to define the identity of women, because both Anna and Rosalie "mirrored their bodies through the eyes of men" (s8). Most of the students expressed a mainly distanced and intellectual attitude towards the characters. As one student wrote: "I couldn't empathize with any of the characters, all of them remained distant to me" (s4). For another student, however, "Anna was the only character I could identify with and sympathize with" (s9). The relationship between Anna and Rosalie was regarded as "abnormally intimate" (s4, s3), and Rosalie was judged with criticism because of "her inability to be a mother" (s7) and "her dominance over Anna" (s3). Rosalie's attitude toward her daughter's youth was regarded as envious, but on the other hand, Anna was seen to envy her mother's happiness and attractiveness in the eyes of men. "It was ironic that [single and childless] Anna had to console her mother for losing something she herself had never possessed", wrote one student (s8). Only one student drew attention to Mann leaving Ken's feelings towards Rosalie unknown in the story.

On the whole, the students reflected a little on Rosalie's passionate feelings and her falling in love, whereas Rosalie's menopausal symptoms, anxieties, fears and inability to accept her advancing age received more general attention. The problematic link between Rosalie's falling in love and her psychical and physiological condition was explained in many ways: "Rosalie felt that through falling in love, she found youth again and her menopausal symptoms disappeared" (s2), "she seemed to have been stunned by the changes in her body, which she thought were as consequences of love" (s3), or "at the same time her increased estrogen levels rejuvenate her physically, she falls in love with a young man" (s11). Rosalie's behaviour and unrealistic desires were interpreted as denial: "Rosalie's falling in love reminds me of mania, a denial and a defence against depression; instead of looking bravely and openly at herself, Rosalie escapes from reality to the entirely unrealistic ecstasy of love" (s8).

\section{Medical issues}

The students explored the symbolic meaning of disability, disease and death from various viewpoints. Obviously, the majority of the writings consisted of reflections on this "medical" dimension of the story. Students regarded the effect of the club foot on Anna's personality formation, artistic inclination and loneliness as evident, but yet "too easy an explanation" (s7). That Ken Keaton had lost one of his kidneys in the war gave "an interesting crack to the Yankee's character", noted one student (s4). The case of Rosalie made students ponder the relationship between soul and body, the physical and psychical, as well as cause and effect as "everlasting questions in medicine" (s11). Whether oestrogen was the cause or the effect of Rosalie's condition was the most common question the students asked. After the middle of the story, when Rosalie celebrated the resumption of her menstruation as a gift of nature, many students recognised bleeding as the first symptom of Rosalie's disease, and thus foresaw her death. One of the students wrote: "When the bleeding started again, it was an alarm bell for me, because we have been taught that the bleeding after menopause always means something bad until else is proved" (sl).

At the end of the story the doctor states his vague hypothesis of a link between Rosalie's growing passion for Ken and her disease. After Rosalie's operation, Dr Muthesius says to Dr Knepperges, "I advise you to adopt my opinion, which is that the whole story started from ... the ovarian cells which, after the menopause, through heaven knows what process of stimulation, begin to develop malignantly". (Mann, ${ }^{6}$ pp 138-9) The students, however, rejected this suggestion, and instead considered the problematic link between the disease, hormonal excretion and falling in love. According to one alternative explanation, "it was provocative to argue that estrogen was the cause of emotions and behaviour; it seems to me as if the author was finally frightened by his tolerance of a middle-aged woman's love, and escaped from the world of explanation by referring to hormones" (s6).

The students found the dramatic end of the story cynical, conservative and unromantic, "hinting that if old people fall in love with younger ones, something ought to be wrong" (s2). The doctor's romantic speech was considered "foolish because no doctor in no way considers an advanced state of cancer romantic. Maybe the author is trying to dramatize the death situation, or maybe I cannot see death as dramatic any more because of my medical studies" (s9).

The way Mann considers the existential questions of disease and death in his "love story" made students ponder the phenomenon of medicalisation. ${ }^{20}$ "We may think that the medicalization of the story was a kind of criticism of emotional romanticism. Emotions were placed under biological control for no other purpose than to show the effect of the tumour. Although we are taught a very biologically-based medicine, I would not like to see things in this way; the small humanist in me rebels against the 'tumour-explains-all' theory" (s3). The students also reflected upon themselves as readers who are studying medicine, and thought about ordinary readers' different reactions. According to a student, "it would be interesting to know if the end solution of the story would be more surprising to non-medical readers" (s8). One of the students described the message of the story for future doctors in the following way: "It reminds me of the wholeness of the human being, and that different persons feel and express their symptoms of illness in various ways. On the other hand, the story showed that the quality of life is most important, not the number of days" (s5).

\section{DISCUSSION}

\section{The students' ways of reading The Black Swan}

The students' medical education and professional interests seemed to guide their construction of the story's meaning and interpretation of its significant themes. They tended to transform the text into an intellectual experience, and "shaped and filtered" it mainly through the perceptual framework they have internalised from their educational culture. ${ }^{18}$ The responses demonstrate how the prior knowledge that the reader brings to the reading process is of crucial importance in understanding the text. ${ }^{14} 16$ The following quotation indicates the student's awareness of the effect of his or her educational culture on him or her to the interpretation of the story:

I wonder how I would have seen the story if I had read it before my medical studies, or if I had studied psychology instead. Perhaps I wouldn't have been so inclined to link Rosalie's behaviour with her increased hormonal production, but have thought that it was her desire for youth that made her fall in love. That she fell ill with cancer was just an 
unhappy event, as sudden deaths usually are. The author doesn't give us the answer. For me it is important to think of this question and not to forget its human and non-medical aspects. In medicine we have a tendency to think very logically and to seek causal explanations (s9).

Because of the dominance of the medical perspective or for more personal reasons, students seldom alluded to their own lives and past experiences, and few commented on their emotional involvement in the experiential world of characters. The age of Rosalie's daughter, her disposition and her role in consoling and advising her mother matched the students' psychology and attitudes as future doctors sufficiently for her to serve as an object of identification. That this identification represented an unusual way to respond to the story is comprehensible because, according to Martin Travers, Mann distances the personal predicament of his characters through the use of irony. The narrator encourages the reader to balance a variety of contrary emotions towards the characters, to sympathise with them while rejecting their positions, and to regret their fates while seeing them as objectively necessary. ${ }^{7}$

The unifying theme that the students dealt with was the complex relationship between the fear of ageing, falling in love, illness and death. Although the question of the causal explanation for Rosalie's condition puzzled the students, they were more inclined to accept the unclear relationship between mind and body as it concerns the aetiology of disease. Thus, the students' "ease" with Mann's ambiguous way of dealing with the problem of life and death expressed their tolerance for complexity and uncertainty. Reading the story also inspired them to consider more the universal and existential questions of medicine. Moreover, the students seemed to understand well the complexity and unconscious nature of human motives as they reflected upon Rosalie's defenses against ageing-namely, her denial of reality and repression of the signs of the disease. The students also understood the main psychological theme of denial, which parallels the ideas of Marguerite De Huzar Allen, who claims that through her denial Rosalie successfully transformed the meaning of events in her life and rejected the widespread image of the older woman as useless and worthless. ${ }^{21}$ In The Black Swan, as in many of his works, Mann described death in naturalistic detail and ironic fashion. Travers" suggests that for Mann, "death appears either as a brute reality, the inevitable culmination of physical decline, or, more metaphysically, as the object longing, a solution to the crisis of alienated sensibility that besets many of Mann's early 'heroes"' (pp. 60-1]. That the students found Rosalie' death at the end of the story unsurprising was because of the influence of the preceding textual cues on their interpretation. However, instead of adopting the doctors' use of medical language and their ironic attitude, or Rosalie's way of romanticising death, the students regarded death as a merciful solution to Rosalie's uncomfortable situation. That young medical students hold no ironic attitude towards death and suffering is understandable, and even desirable.

Dislike of and negative responses to the story may stem either from the students' dissatisfaction with the story or from their difficulty in understanding it. Besides certain stylistic features, such as dated and over-romantic language, the oldfashioned image of a woman that Mann portrayed through Rosalie and her daughter Anna annoyed students. Students felt that because the author is a man, he was incapable of writing about the experiences of the opposite gender. This impression of the uncanny is probably linked to the students' lack of historical perspective in reading historical novels. The world has changed enormously over the past 50 years, and people's manners, their ways of expression and even, perhaps, their feelings have evolved as well. Without historical knowledge and biographical information on the author's sexual orientation, as well as on his tendencies of disguising it in his fiction, a more apt interpretation could hardly be expected. Had the students reflected more upon the period in which the story was written, and been aware of the practices of stigmatisation that homosexuals had to contend with around 1900, they would certainly have considered this. In the mid-1900s, homosexuals were still considered as ill from a medical perspective, and subjected to various treatments. ${ }^{22}$ The same holds true for recognising the very symbolic nature of Mann's writing: without focusing on the story by means of a deeper textual analysis, the students would understandably tend to read the story literally. Although the students noticed Rosalie's physical disability, they were largely unaware of Mann's use of physical abnormalities as a metaphor for sexual deviation or, as in the case of Anna, as a representation of the alienated status of the artist in society. ${ }^{7}$ That Rosalie's feelings during her romantic episode were largely absent from the student's writings may originate from this same feeling of strangeness. The students avoided moralising Rosalie's love affair as such perhaps because the openly erotic and uncontrolled nature of the relationship made the students unwilling to deal with it.

\section{CONCLUDING REMARKS}

If literature is intended to enhance medical students' capacity to understand the human dimension of medical practice, what can be said about the potential of reading Mann's story? First, understanding itself is a difficult phenomenon to define. Carl Bereiter, ${ }^{23}$ for example, states that to understand a person is intimately bound with the understanding of the underlying motives, basic values, dispositions, thought patterns and behaviour of the person. Second, in the case of literature, this relationship is even more complex because the reader is part of the object of understanding, and because the understanding of the fictional character is based on the feelings and thoughts of that character, created in the reader's mind through the process of reading. ${ }^{24}$

Although the mere act of reading itself can stimulate the reader's self-reflection and satisfy his or her intellectual curiosity, tutored exploration and extra-textual knowledge seem necessary if the potential of literature is to enrich the students' capacity to see things in a new way. That an individual reader determines the meaning according to his or her subjective way is supported by research on perception. As cognitive psychology has shown, perception is to process information from the environment according to one's cognitive structures, developed through the particular culture and environment in which one has grown up. ${ }^{25}$

How to approach literature in medical education depends on the text used, the educational aims, the interests and characteristics of the students, as well as on the teacher or the tutor. That the teacher gets to know the students' initial responses represents a good starting point for further exploration. Besides the medical issues, the multilayered The Black Swan contains several questions relevant to medical practice. Dealing with the elements of the text that the students neglected or regarded as strange may increase their selfunderstanding and encourage them to question their habitual ways of interpreting human behaviour. One's sensitivity to perceiving hidden meanings may be developed too. Researchers have observed that medical students openly engage with the literature as long as the characters exhibit little defiance or disrespect towards doctors, but subjects such as race, gender, social class and sexual identity easily find resistance among students. ${ }^{26}$ More than the ideas and the events of the story of The Black Swan, the writing period seemed to evoke odd feelings 
and to distance the students. To better understand the story, the students would benefit from reading Mann's biography, as well as the period of writing, the nature of artistic creativity and psychology. Although to evaluate the students' individual responses to literature and to reflect upon them is important, the teacher or tutor with a strong background in literature, literature theories and psychology is equally important in enhancing the students' understanding. Psychological theories, for example, provide categories for understanding that help us to intuit the workings of the human psyche, and these intuitions, on the other hand, become our conceptual understanding of life. Through literature we gain "a phenomenological" grasp of experience that cannot be derived from theory alone. $^{27}$

This study has described and reflected on medical students' initial responses to the imaginative literature. Despite the widely accepted notion of the educative value of arts and literature in medical education, the conditions for using this potential require more exploration. More study is needed to examine the various ways of working with literature in medical education if we are to go beyond the level of theoretical hypothesising. ${ }^{28}$ To focus on experiences in reading literature is to deal with art. Perhaps we ought to accept the fact that many such things happen in reader's minds that are beyond conscious reflection. As Anna stated in The Black Swan, "certain diseases are too good to be taken to a doctor" (Mann, ${ }^{6}$ pp 113); perhaps true literary understanding is too intricate to grasp completely.

\section{Authors' affiliations}

Aino-Maija Lahtinen, Department of Education, Faculty of Behavioural Sciences, University of Helsinki, Helsinki, Finland

Martina Torppa, Department of General Practice/Unit of General Practice, Institute of Clinical Medicine, Faculty of Medicine, University of Helsinki, Finland

\section{REFERENCES}

1 Greaves D, Evans M. Medical humanities. J Med Ethics Med Humanit 2000;26:1-2.

2 Schweizer H. To give suffering a language. Lit Med 1995;14:210-21.

3 Coulehan JL. Tenderness and steadiness: emotions in medical practice. Lit Med 1995; 14:222-36

4 Barker P. Working with the metaphor of life and death. J Med Ethics Med Humanit 2000;26:97-102
5 Rolfe G. 'A lie that helps us see the truth': research, truth and fiction in the helping professions. Reflective Pract 2002;3:89-102.

6 Mann T. The Black Swan. [translated by Trask WR.] Los Angeles: University of California Press, 1990/1953.

7 Travers M. Thomas Mann. London: Macmillan Education, 1992

8 Mendelssohn P de. "Nachbemerkungen des Herausgebers," in Thomas Mann. Späte Erzählungen. Frankfurt, 1981, 527f, in De Huzar Allen M, Denial and acceptance. Narrative patterns in Thomas Mann's Die Betrogene and Kleist's Die Marquise von O. Ger Rev 1989:64:121-8.

9 Dietl J. Thomas Mann's last novella 'The Black Swan': the tragic story of a postmenopausal woman. Eur J Obstet Gynec Reprod Biol 2004; 113:255-7.

10 Vaget HR. Thomas Mann Kommentar zu sämtlichen Erzählungen. Munich: Winkler, 1984:312.

11 Straus NP. Introduction. The Black Swan. [Translated by Trask WR.] Los Angeles: University of California Press, 1990/1953, v-xiv.

12 Lange-Kirchheim A. Gender trouble in Thomas Mann's early novella Der Kleine Herr Friedmann (Little Herr Friedmann). Paper presented at the 21 st International Literature and Psychology Conference, 30 June -5 July 2004, Arles, France. http://www.clas.ufl.edu/ipsa/2004/proceedg.htm (accessed17 Mar 2007).

13 Torppa M, Lahtinen A-M. Responding to "The Black Swan"-aspects of medical students' professional growth. Paper presented in the Second Annual Conference, Medicine and the Humanities: Towards Interdisciplinary Practice, 19-21, July 2004, University of Wales, Swansea, Great Britain.

14 Earthman AE. Creating the virtual work: readers' processes in understanding literary texts. Res Teach Engl 1992;26:351-85.

15 Holland NN. Reading readers reading. In: Cooper CR, ed. Researching response to literature and teaching of literature:points of departure. Norwood, NJ: Ablex 1985:3-21.

16 Fish S. Is there a text in this class? The authority of interpretive communities, Cambridge, MA : Harvard University Press, 1980.

17 Rosenblatt LM. The transactional theory of reading and writing. In: Ruddell RB, Ruddell MR, Singer $\mathrm{H}$, eds. Theoretical models and processes of reading. [4th edn]. Newark, DE: International Reading Association, 1994:1057-92.

18 Holland NN. The dynamics of literary response. New York: Columbia University Press, 1968.

19 Holland NN. The critical I. New York: Columbia University Press, 1992.

20 Mintzes B. Direct to consumer advertising is medicalising normal human experience. BMJ 2002;324:908-11.

21 De Huzar Allen M. Denial and acceptance. Narrative patterns in Thomas Mann's Die Betrogene and Kleist's Die Marquise von O. Ger Rev 1989;64:121-8.

22 Hart G, Wellings K. Sexual behaviour and its medicalisation: in sickness and in health. BMJ, 2002;4:896-9.

23 Bereiter C. Education and mind in the knowledge age. London: Lawrence Erlbaum, 2002.

24 Poulet G. Criticism and the experience of inferiority. In: Tompkins J, ed. Reader response criticism. From formalism to post-structuralism [translated by Macksey $C$ and Macksey R]. Baltimore: Johns Hopkins University Press, 1980:41-9.

25 Neisser U. Cognition and reality. Principles and implications of cognitive psychology. San Francisco: WH Freeman and Company, 1976.

26 Wear D, Aultman JM. The limits of narrative: medical student resistance to confronting inequality and oppression in literature and beyond. Med Educ 2005;39: 1056-65

27 Paris BJ. Imagined human beings: a psychological approach to character and conflict in literature. New York: New York University Press, 1997

28 Ahlzen R. The doctor and the literary text-potentials and pitfalls. Med Health Care Philos 2002;5:147-55.

\section{Take advantage of BMJ Journals' remarkable catalogue of titles with Related} Collections

No busy professional has time to browse through all pertinent journals to find relevant articles, but with Related Collections you no longer have to. Follow the "Related Collections" link from any article and use the "Show Collections from other Journals" to expand your search across all BMJ Journals. Or simply follow the "Browse by topic" link on the home page. By setting up your own collections and receiving email alerts every time an article is added to your chosen area, you can build up your own significant body of knowledge. 